\title{
Pulverization of fibrous mineral wool waste
}

Original article

Yliniemi $\mathrm{J}^{1}$, Laitinen $\mathrm{O}^{1}$, Kinnunen $\mathrm{P}^{1,2}$, Illikainen $\mathrm{M}^{1,{ }^{*}}$

${ }^{1}$ Fiber and Particle Engineering Research Unit, P.O. Box 4300, 90014 University of Oulu, Finland

${ }^{2}$ Department of Civil and Environmental Engineering, Imperial College London, London SW7 2BU, United Kingdom

${ }^{*}$ Corresponding author

mirja.illikainen@oulu.fi

$+358405885904$

\begin{abstract}
The total annual volume of mineral wool waste in the 27 European Union (EU27) countries is expected to increase to 2.5 million tons per year by 2020. Unfortunately, mineral wool wastes are often considered unrecyclable because their physical characteristics make them difficult to process. In many cases, the problem is caused by the material's fibrousness. However, no studies have considered comminution methods for mineral wools. The objective of the present study is to investigate how various comminution mechanisms affect mineral wools' physical characteristics, including appearance, bulk density, and fiber length and width. The study's results show that compression-based methods (vibratory disc mill and hydraulic press) completely break down mineral wools' fibrousness, whereas methods based on high cutting speeds affect bulk density and fiber length only moderately. In addition, the present study identifies a rapid method that can be used in a novel way to analyze a large number of mineral wool fibers.
\end{abstract}

Keywords: man made vitreous fiber (MMVF); mineral wool fiber; comminution; milling; fiber conversion 


\section{Introduction}

Mineral wools, including rock and glass wools, are the most common insulating materials in the world. Rock wool (RW) is the principal type produced, glass wool (GW) is second, being produced at about one-third of the volume of RW, and slag wool is no longer used in significant volume [1]. Synthetic mineral wool fibers are produced at high temperatures by melting mineral raw materials [2]. The molten mixture is fiberized by a highspeed spinning process, and a small quantity of additive are used to bind the fibers together (typically ureaphenol-formaldehyde-based solutions). Mineral or silicon oils may be added to reduce generation of dust and make the product water repellent.

Although mineral wool production creates waste and by-products, including mineral wool offcuts, the main mineral wool waste stream is generated by building construction and demolition. In 2010, the total volume of mineral wool waste produced in the 27 European Union (EU27) countries was 2.3 million tons, and it is expected to be 2.5 million tons annually by 2020 [3].

Unfortunately, mineral wool waste is often unrecyclable [3]. Applications that use mineral wool wastes include ceramics [4, 5], cement and wood-polypropylene composites [6-9], fiber-based composites [10], gypsum board [11-13], briquettes [14, 15], tile [16], and most recently geopolymers [17, 18]. However, use of post-consumer and fine mineral wool waste is still extremely low, the barriers to its use being related to technical, economic, and health issues [16].

Two specific challenges are the fibrous nature and low density of the material. The bulk density of mineral wools varies between $20-200 \mathrm{~kg} / \mathrm{m}^{3}$, whereas the true density can be up to $3000 \mathrm{~kg} / \mathrm{m}^{3}$. This means that the total porosity can be up to $99 \%$ [1]. In other words, $99 \mathrm{~cm}^{3}$ of each $100 \mathrm{~cm}^{3}$ is air. Not only is it expensive to transport their bulk, but it is also difficult to use mineral wools in cement, gypsum, and geopolymer applications, in which water demand must be minimized and in which adding a fibrous material drastically reduces flowability.

Surprisingly, although this problem has often been noted, to the best of our knowledge, no study has addressed increasing mineral wools' bulk density and decreasing their fibrousness. The only paper related to conversion of mineral wool waste destroyed the fiber structure thermally by microwaves [19]. Typically, the studies targeting the utilization of mineral wools have not addressed processing methods in detail. In addition, studies typically have not reported physical characteristics, including fiber length and material density.

The present study investigated various methods of comminuting mineral wool, as effective comminution conditions are crucial to recycling mineral wool waste. The study's objective was to examine how various comminution mechanisms affected mineral wools' physical characteristics, including appearance, bulk density, and fiber length and width. The optimal comminution result is dependent on the preferred application. For example, as cement additive or geopolymer precursor, the material has to be powder. However, for composite-type products fibers with certain length may be preferred.

In addition, this study implemented a rapid method in a novel way to determine the distribution of mineral wool fiber lengths and widths. Typically, lengths and widths are analyzed using a scanning electron or optical microscope [20]. The proposed approach can analyze up to 200,000 individual fibers per sample point and analysis takes time only about 3 min. 


\section{Experimental}

\subsection{Mineral wools}

The mineral wools used were cutting and process waste from mineral wool production plants. They had typical chemical compositions of rock wool and glass wool ( $\mathrm{SiO}_{2}: \sim 40 \mathrm{w} \%, \mathrm{Al}_{2} \mathrm{O}_{3}: \sim 16 \mathrm{w} \%, \mathrm{Fe}_{2} \mathrm{O}_{3}: \sim 9 \mathrm{wt} \%, \mathrm{CaO}+\mathrm{MgO}: \sim 29$ w\%, $\mathrm{Na}_{2} \mathrm{O}+\mathrm{K}_{2} \mathrm{O}$ : $2 \mathrm{w} \%$ for rock wool and $\mathrm{SiO}_{2}: ~ 56 \mathrm{w} \%, \sim \mathrm{Al}_{2} \mathrm{O}_{3}: ~ 2 \mathrm{w} \%, \mathrm{Fe}_{2} \mathrm{O}_{3}: ~ \sim 1$ wt\%, $\mathrm{CaO}+\mathrm{MgO}: \sim 10 \mathrm{w} \%$, $\mathrm{Na}_{2} \mathrm{O}+\mathrm{K}_{2} \mathrm{O}: \sim 16 \mathrm{w} \%$ for glass wool). Figure 1 presents their appearance.

\subsection{Comminution methods}

The present study tested five comminution methods that used varying types of milling principles. All five are discussed below.

\section{Granulator 200 Series (Rapid)}

The Rapid 200 Series granulator (granulator) was initially developed for plastic recycling. To use it, 30-100 g of material was added manually to the feeding container, from which it was dropped onto knives rotating at high speeds, which cut the material until it fitted through a screen (Appendix A), the size of which was adjustable from 2-6 mm, after which it was collected in bags.

\section{ZRI homogenizer (Haarla Oy)}

An unconventional comminution method is the laboratory-scale, high-frequency dispergator (ZRI), which consists of a stator in the form of a series of concentric rings containing slots (Appendix B). Embedded between the stator rings is a rotor with a frequency of $260 \mathrm{~Hz}$. ZRI was originally developed for pulp fiber dispersion [21]. The material can be added as a suspension or slurry, which is fed into the center of the stator and forced to flow outwards through the concentric rings. During our experiments, the gap between the dispergator stator and the rotor was on the order of $1 \mathrm{~mm}$. A manual valve was used to control the through-flow and pressure, which was set at 10 bar. After the material passes through the dispergator, it can be either collected or directed back to the feeding container, meaning that material can be processed in a loop for as long as desired. One loop of 1000-ml suspension takes 3-5 s. The present study used 30-50 g of mineral wool dispersed in 1000 $\mathrm{ml}$ of water and looping times of 1-6 min. The processed suspension was collected in a plastic container, filtered, and dried at $100^{\circ} \mathrm{C}$ for $24 \mathrm{~h}$ prior to analysis.

\section{UPZ Fine Impact Mill (Hosokawa Alpine)}

Fine impact mills are used in many branches of industry, but most applications are in the chemical, foodstuff, and pharmaceutical industries [22]. The original material (30-100 g) was added to the feeding container manually. A feeding screw carries the material to the mill chamber, which contains one rotating and one stationary pin disc (Appendix $\mathrm{C}$ ). The high-speed pin disc generates an under pressure that carries the material to the container that collects it after processing.

The present study used feeding-screw speeds of 100-188 rpm and pin-disc speeds of $12,000 \mathrm{rpm}, 16,000 \mathrm{rpm}$, and 22,000 rpm. The study also conducted experiments with a cryogenic milling unit, for which the feed material was cooled using liquid nitrogen and then milled using the same parameters used for the process without the cryogenic unit.

\section{Hydraulic press 30 ton (ABCO Mega)}


The fourth method used was a hydraulic press (press). In this method, the material was loaded into a cylindrical steel mold $\left(\mathrm{V}=50.3 \mathrm{~cm}^{3}\right.$ ) in batches of $5 \mathrm{~g}$ for $\mathrm{GW}$ and $10 \mathrm{~g}$ for RW (Appendix D). Below and above the material were steel plates providing flat, horizontal surfaces for the piston, which was $4 \mathrm{~cm}$ in diameter. The mold was placed between the piston and the pedestal, a force of 10 tons was applied to the piston, and the pressure was maintained for $30 \mathrm{~s}$. The samples were collected in plastic containers and mixed with a spoon to break up clumps of pressed material.

\section{Vibratory disc mill RS200 (Retsch)}

The vibratory disc mill (RS200) is designed to pulverize concrete, glass, ceramic, and cement clinkers [23]. To use this method, material was loaded in batches of 10-15 $\mathrm{g}$ into a grinding dish containing a grinding disc and grinding ring (Appendix E). In the present study, the milling speed used was $1500 \mathrm{rpm}$, and the milling time was $30 \mathrm{~s}$.

Appendix $\mathrm{F}$ presents details the variable parameters of the experiments. The variable parameters were optimized to produce material of uniform quality and Table 1 presents the experiments that best represent each comminution method. The samples from these experiments were subjected to further analysis.

The loose bulk densities of the comminuted wools were determined according to a standard EN 1097-3 [24] that was developed for natural and artificial aggregates. Therefore, it can be argued that this standard is not generally suitable for wools. However, we considered that this standard provides a rough estimate of the transformation of the material. The untapped and tapped densities of the samples that were comminuted into powder were determined according to standard EN 1237 [25]. When densities were compared, ordinary Portland cement (OPC, Valkosementti by Finnsementti) was used as a reference material.

A field emission scanning electron microscope (FESEM, Zeiss Ultra Plus) was used to analyze the original and comminuted materials after carbon coating. The distance between the sample and the beam tip was $4.3 \mathrm{~mm}$, and the acceleration voltage used was $5 \mathrm{kV}$.

\subsection{Tube-flow fractionation methods (Large fractionator and Small fractionator)}

The analysis of fiber length and width distributions were done by using tube flow fractionation methods. Two fractionation equipment with similar principles, but different size class were used: Large fractionator flow velocity during fractionation is $92.5 \mathrm{ml} / \mathrm{s}$, inner tube diameter is $16 \mathrm{~mm}$ and CCD camera resolution is $6.4 \mu \mathrm{m}$, while small fractionator flow velocity is $7.7 \mathrm{ml} / \mathrm{s}$, inner tube diameter is $4 \mathrm{~mm}$ and CCD camera resolution is $1.6 \mu \mathrm{m}$ [26]. Small fractionator were used to analyze samples from hydraulic press and Vibratory disc mill RS200 due to their smaller particle size compared to other samples.

Mineral wool samples were diluted with deionized water in order to form suspension with $0.3 \mathrm{~m} \%$ concentration. Before dilution, the mineral wool samples were wetted with few milliliters of ethanol and manually mixed with glass rod. Next deionized water and few drops of detergent (Fairy [Procter \& Gamble] to act as a dispersant) were added and then diluted samples were stirred for at least 30 min with a magnetic stirrer. Diluted and dispersed samples were applied for particle size measurement with tube flow fractionation method.

Figure 2 presents a schematic picture of the tube flow fractionation method and as mentioned earlier both fractionators (large and small) use same fractionation principle. The theory of the fractionation principle has been described in more detail in [27]. In brief, when the sample is injected into the tube, the particles are 
distributed randomly. As the flow begins and proceeds, the slight turbulence in the transition flow regime begins to move the particles inside the flow. The probability of being captured by the faster middle flow is higher for particles with one long dimension (e.g. high aspect ratio) or multiple long dimensions (e.g. flake type particles) than for particles with short dimensions (e.g. small dust type particles). Thus, the large particles tend to concentrate at the front end of the flow and finally come out from the tube first.

The variables of interest during fractionation, including flow velocity, pressure, temperature, sample volume, and consistency, are all maintained precisely at a constant level, as each variable has a direct effect on the fractionation. When fractionation conditions are kept constant, certain particle sizes always exit the flow tube at the same time and ensuring high repeatability and reliability. The variation (standard deviation) of the combined sample fractionation and optical image analysis has been determined to be $4.5 \%$ and based on 23 parallel sample analysis [28].

The wool particles in the fractionated particle-water suspension were visualized with a high-definition CCD camera unit, which captured up to 2000 individual pictures including up to 200,000 individual particles analyzed per sample [29]. Image analysis of individual particles was accomplished by applying a Metso IMG image analysis software with practical image analysis sensitivity around $4 \mu \mathrm{m}$ for large fractionator and $1 \mu \mathrm{m}$ for small fractionator. Image analysis procedure can be divided in six steps: (1) image formation, (2) image scanning, (3) feature detection (count, shape, size etc.), (4) feature analysis, (5) data processing and (6) data presentation [30]. Fig. 3 presents four example pictures a wool powder samples taken after tube flow fractionation ( $\mathrm{a}$ and $\mathrm{b}$ are imaged by Large fractionator while $\mathrm{c}$ and are imaged by Small fractionator).

\section{Results and Discussion}

\subsection{Appearance of comminuted mineral wools and notes about methods}

The appearance of the comminuted mineral wools was greatly affected by the various comminution methods tested (Appendices G-I). The granulator produced ball-shaped, lumps of a size relative to the screen used (Appendix G). Some material stuck in the screen and on the grating below it, but otherwise the method worked properly.

The material collected after using the UPZ method (Appendix G) was smaller than the samples from the granulator. To feed the GW into the UPZ, it was necessary to first comminute it with the granulator using a 2$\mathrm{mm}$ screen, as the GW was in larger lumps than the RW (Figure 1). At the lower pin-disc speeds $(12,000 \mathrm{rpm}$ and 16,000 rpm), loss of material to the feeding container, pipes, and pin wheels was a problem. However, at $22,000 \mathrm{rpm}$, much less material was lost. This difference in loss was caused by the differing pressures produced by the differing pin-disc speeds. For example, at $12,000 \mathrm{rpm}$, the pressure inside the mill chamber was $-3-4$ mbar, whereas at 22,000 rpm it was -30-35 mbar, which provided suction sufficient for the material flow. In addition, at the highest pin-disc speed, a higher temperature was measured: $50^{\circ} \mathrm{C}$ (for other runs temperature was around $\left.30^{\circ} \mathrm{C}\right)$.

Cooling by immersion in liquid nitrogen appeared to have no effect on the materials' brittleness. Although counter-intuitive, this observation is explained by the process for manufacturing mineral wools. They are produced by rapidly cooling melted mineral raw materials (waste glass, sand, etc.) into amorphous, fibrous products. Glass transition temperature for similar glass as RW is around $700^{\circ} \mathrm{C}$ [31] and for similar glass as $\mathrm{GW}$ is above $600^{\circ} \mathrm{C}$ [32]. Therefore, mineral wools are already below the glass-transition temperature and thus not made more brittle by cooling with liquid nitrogen. 
After filtering and drying, the material obtained using the ZRI method was lumpy, with balls of about $5 \mathrm{~mm}$ in diameter (Appendix H). For both types of mineral wool, the material suspension at first had a variable flow that became more homogenous within the first 1-3 minutes of looping. A better feed for the GW was obtained if it was first comminuted using a granulator and a 2-mm screen. In order to check if mineral wools dissolved during the ZRI processing (as it could have effect on the fiber width and length), conductivity and pH were measured from the suspensions. The RW conductivity was $178 \mu \mathrm{S} / \mathrm{cm}$ and its $\mathrm{pH}$ was 8.8 and the GW conductivity was $285 \mu \mathrm{S} / \mathrm{cm}$ and its $\mathrm{pH}$ was 9.9, as measured from the suspensions. This indicates that no dissolution occurred during ZRI processing and that the comminution was due only to the mechanical forces.

After using the press and RS200 methods, the material obtained (Appendix I) was in powder form, which was a more drastic change in the appearance of the mineral wools than the other methods produced. The benefit of these two methods was very rapid comminution: 30 seconds. However, as the steel mold of the press and the grinding container of the RS200 were small, only small sample sizes of 5-15 g could be comminuted at one time.

\subsection{The densities of the comminuted mineral wools}

The loose bulk densities of the comminuted samples (Figure 4) confirmed the visual observations discussed in the previous section. The press and RS200 produced materials that were much denser than those produced by other methods. The original RW was denser than the original GW (Figure 4); therefore, the comminuted RW samples were denser than the comminuted GW samples.

As Figure 5 shows, both the untapped and tapped densities of the press and RS200 powder samples showed the same trend as in Figure 4. The RS200 produced denser material than did the press, and the RW samples had higher densities than the GW samples. Because two of the potential uses of comminuted mineral wools are as raw material for geopolymers and additives for concretes, these powder samples were compared with OPC. The tapped densities of comminuted mineral wools were lower than those of OPC, but the difference originated from the higher material density of the OPC $\left(3.4 \mathrm{~g} / \mathrm{cm}^{3}\right)$ (Figure 5 ).

\subsection{Fiber lengths and widths}

The unground GW consisted of longer fibers than the RW (average lengths of 612 and $424 \mu \mathrm{m}$, respectively) (Figures 6 and 7 and Table 2). Interestingly, independent of the original samples, all comminution methods produced the same trend in fiber-length distributions. From longest to shortest, the order of the fiber lengths yielded by various comminution methods was ZRI > granulator $>$ UPZ> press $>$ RS200. In other words, ZRI affected fiber length the least, and RS200 affected it the most. The high density of the samples comminuted using the press and RS200 methods (Figure 5) can be explained by their very short fiber lengths (averaging 37-87 $\mu \mathrm{m})$.

None of the comminution methods decreased fiber width (Table 2), indicating that the fibers were not crushed, but rather truncated. In the samples comminuted using the press and RS200, the fiber widths increased slightly. It was determined by the Metso IMG image analysis and FESEM-analysis (Figure 8) that the fibers were partly squashed/agglomerated by the compressive forces of the press, thereby increasing their width. The increased widths caused by the RS200 method can be explained by the low average aspect ratio (3.2-4.6) of the fibers. When the aspect ratio is so low, the fractionator may misidentify some fiber lengths as widths, thereby increasing the average of the widths. Were a longer milling time used with the RS200 method, it would be expected that the widths would also decrease. 
Comminuting wool samples using the RS200 method produced a high quantity of dust-like particles (Table 2 and Figure 9). In contrast, the press method produced a small amount of dust, but the comminuted material still had a fibrous appearance (aspect ratio > 7). The RS200 method involved intensive mechanical pressure and abrasion of the sample between the grinding dish and ring, which explains why this method produced the shortest fiber lengths. The press method produced glassy fiber networks one atop the other, and when pressure was applied to them, fibers cut off other fibers. In both the RS200 and press methods, comminution depends on the brittleness of the mineral wool fibers: once the mineral wools are compressed, the fibers cannot distribute the force applied to them over a large area, and therefore they are broken relatively easily.

For regulatory purposes, most countries define dangerous "respirable fibers" (that is, those with the ability to reach the lungs, particularly their alveolar regions) using the World Health Organization (WHO) criteria: fibers longer than $5 \mu \mathrm{m}$ and less than $3 \mu \mathrm{m}$ in diameter with aspect ratios greater than 3 . In the present study, the processed fibers were safe because they had diameters greater than $3 \mu \mathrm{m}$. However, this issue must be considered if older C\&D mineral wool waste is to be comminuted.

\section{Conclusions}

This study investigated methods of comminuting mineral wools, showing that various methods produce various fiber lengths. Complete removal of fibrous nature of the mineral wool makes it suitable raw material for geopolymers and cement application. In that case, vibratory disc mill was found to be the best comminution method.

Based on the experiments conducted in this study, the following conclusions were drawn.

1. Comminution methods based on compression and abrasion completely destroy mineral wools' fibrousness, whereas methods based on high speeds, including the ZRI homogenizer, the UPZ fineimpact mill, and (blade)-granulation, only moderately decrease bulk density and fiber lengths.

2. Comminution does not decrease the width of mineral wool fibers. Only the fiber length is affected.

3. Comminution results are independent of type of mineral wool. It can be expected that all glassy mineral wools behave similarly, including old C\&D mineral wool waste.

4. Tube-flow fractionation methods provide a rapid and easy way to analyze the length and width of mineral wool fibers.

5. If the aim is to decrease mineral wool bulk density and fiber length as much as possible, comminution methods based on compression and abrasion, including pan mills, ball mills, rod mills or table-roll mills, may be the best solutions on an industrial scale.

6. To pulverize mineral wool boards, pre-treatment with granulator-type or cutting mills may be necessary.

\section{Acknowledgements}

This work was conducted under the auspices of the Geodesign Project, supported by the Finnish Funding Agency for Technology and Innovation (Tekes) and various companies (Boliden Harjavalta Oy, Destamatic Oy, Fortum Power and Heat Oy, Paroc Group Oy, Saint-Gobain Rakennustuotteet Oy, and Suomen Erityisjäte Oy). Jarno Karvonen, Elisa Wirkkala, and Jani Österlund are acknowledged for their contributions to the laboratory analyses. Special thanks to Pontus Lindberg (Paroc Group Oy) for his valuable advice on the comminution experiments. 


\section{References}

1. Müller A, Leydolph B, Stanelle K (2009) Recycling mineral wool waste-Technologies for the conversion of the fiber structure Part 1. Interceram 2009:378-381.

2. Papadopoulos AM (2005) State of the art in thermal insulation materials and aims for future developments. Energy Build 37:77-86. doi: 10.1016/j.enbuild.2004.05.006

3. Väntsi O, Kärki T (2013) Mineral wool waste in Europe: a review of mineral wool waste quantity, quality, and current recycling methods. J Mater Cycles Waste Manag 2013:1-11. doi: 10.1007/s10163-013-0170-5

4. Pranckevičienè J (2011) Impact of mineral wool production waste on properties of sintered ceramics. Dissertation, VGTU leidykla „Technika“

5. Kizinievič O, Balkevičius V, Pranckevičienè J, Kizinievič V (2014) Investigation of the usage of centrifuging waste of mineral wool melt (CMWW), contaminated with phenol and formaldehyde, in manufacturing of ceramic products. Waste Manag. doi: 10.1016/j.wasman.2014.01.010

6. Cheng A, Lin W-T, Huang R (2011) Application of rock wool waste in cement-based composites. Mater Des 32:636-642. doi: 10.1016/j.matdes.2010.08.014

7. Hagerman RM (1987) Mineral wool waste cement. Patent.

8. Lin W-T, Han T-Y, Huang C-C, et al (2012) Using Rock Wool Wastes as Partial Replacement of Cement in Cement-Based Composites. Adv Sci Lett 8:489-494.

9. Väntsi O, Kärki T (2014) Utilization of recycled mineral wool as filler in wood-polypropylene composites. Constr Build Mater 55:220-226. doi: 10.1016/j.conbuildmat.2014.01.050

10. Felegi J Jr, Kehrer KP (1990) Composite fiberboard and process of manufacture. Patent.

11. Ali MH (1985) Fire resistant gypsum board containing mineral wool fibers and method. Patent.

12. Cadotfe JE, Cadotfe JE (1970) Production of Water-Laid Felted Mineral Fiber Panels Including Use of Flocculating agent. Patent.

13. Long WJ (1984) Mineral fiber-containing paper for the production of gypsum wallboard. Patent

14. Talling BLO, Sarudis M (1995) Raw material briquette for mineral wool production and process for its preparation and its use. Patent.

15. Heinelt W (1996) Method and apparatus for treating mineral wool wastes. Patent.

16. Dunster A (2007) Characterisation of mineral wastes, resources and processing technologies-Integrated waste management for production of construction material. Case Study: Waste mineral fiber in ceiling tile manufacture. 
17. Yliniemi J, Kinnunen P, Karinkanta P, Illikainen M (2016) Utilization of Mineral Wools as Alkali-Activated Material Precursor. Materials 9:312.

18. Kinnunen P, Yliniemi J, Talling B, Illikainen M (2015) Rockwool waste in fly ash geopolymer composites. J Mater Cycles Waste Manag 1-8.

19. Müller A, Leydolph B, Stanelle K (2010) Recycling Mineral Wool Waste - Technologies for the Conversion of the Fiber Structure, Part 2. Interceram 59:39-45.

20. Širok B, Blagojević B, Bullen P (2008) 8 - Applying the Visualisation method to Measuring the Thickness of Mineral Wool Fibres. In: Miner. Wool. Woodhead Publishing, pp 106-112

21. Suopajärvi T, Kekäläinen K, Illikainen M, Niinimaki J (2009) Effect of High Intensity Treatment on Mechanical Properties of Low Consistency Pulp. Proc TAPPI EPE 1-11.

22. Hosokawa A HOSOKAWA ALPINE Aktiengesellschaft. https://www.hosokawa-alpine.com/powderparticle-processing/machines/fine-impact-mills-and-classifier-mills/upz-fine-impact-mill-ultraplex/. Accessed 20 Dec 2016

23. Retsch R (2017) Vibratory Disc Mill RS 200 - Retsch - high end fineness and speed. http://www.retsch.com/products/milling/disc-mills/rs-200. Accessed 10 Jan 2017

24. EN 1097-3 (1998) Tests for mechanical and physical properties of aggregates. Part 3: Determination of loose bulk density and voids.

25. SFS EN 1237 (1995) Fertilizers. Determination of bulk density (tapped).

26. Kekäläinen K (2016) Microfibrillation of pulp fibres. The effects of compression-shearing, oxidation and thermal drying. Doctoral thesis, University of Oulu

27. Laitinen O, Kemppainen K, Stoor T, Niinimäki J (2011) Fractionation of pulp and paper particles selectively by size. BioResources 6:672-685.

28. Laitinen O, Niinimaki J (2014) Fractional Study of the Microfibrillated Cellulose. Tappi J 13:49-55.

29. Laitinen O, Joensuu I, Niskanen T, Niinimäki J (2014) Analysis of the external fibrillation. Int Papwirtsch 57:46-52.

30. Karinkanta P, Laitinen O (2017) Use of tube flow fractionation in wood powder characterization. Biomass \& Bioenergy 99:122-138.

31. Yilmaz S, Özkan O, Günay V (1996) Crystallization kinetics of basalt glass. Ceram Int 6:477-481.

32. Achchaq F, Djellab K, Beji H (2009) Hydric, morphological and thermo-physical characterization of glass wools: From macroscopic to microscopic approach. Constr Build Mater 10:3214-3219 
Table 1. Representative Experiment for Each Comminution Method*

\begin{tabular}{|l|l|}
\hline Method & Parameters \\
\hline Granulator & Sieve size: $2 \mathrm{~mm}$ \\
\hline UPZ & Feeding speed: $188 \mathrm{rpm} ; 22,000 \mathrm{rpm}$ \\
\hline ZRI & $260 \mathrm{~Hz}$; Fed as $5 \mathrm{~m} \%$ water suspension; Looping time: 4 min \\
\hline Press & Pressure: 10 tons $/ 12.6 \mathrm{~cm}^{2}$; Pressing time: $30 \mathrm{~s}$ \\
\hline
\end{tabular}

* The samples from these experiments were subjected to more detailed analysis.

Table 2. Mineral Wool Fiber Length, Width, Aspect Ratio, and Dust Content as Determined by Fractionators

\begin{tabular}{|l|l|c|c|c|c|}
\hline Sample & Fractionation method & Fiber length $[\mu \mathrm{m}]^{*}$ & Fiber width $[\mu \mathrm{m}]^{* *}$ & Aspect ratio $[\mathrm{l} / \mathrm{d}]^{* * *}$ & ${\text { Dust }[\%]^{* * * *}}^{*}$ \\
\hline RW & Large fractionator & 424 & 7.6 & 55.7 & 1.2 \\
\hline RW Granulator 2mm & Large fractionator & 387 & 7.6 & 50.6 & 1.2 \\
\hline RW ZRI 4min & Large fractionator & 365 & 8.1 & 45.0 & 1.5 \\
\hline RW UPZ 22000rpm & Large fractionator & 191 & 7.7 & 24.7 & 2.0 \\
\hline RW Press & Small fractionator & 76 & 10.3 & 7.4 & 3.0 \\
\hline RW RS200 & Small fractionator & 37 & 11.7 & 3.2 & 19.0 \\
\hline
\end{tabular}

\begin{tabular}{|l|l|c|c|c|c|}
\hline Sample & Fractionation method & Fiber length $[\mu \mathrm{m}]^{*}$ & Fiber width $[\mu \mathrm{m}]^{* *}$ & ${\text { Aspect ratio }[\mathrm{l} / \mathrm{d}]^{* * *}}^{\text {Dust }[\%]^{* * * *}}$ \\
\hline GW & Large fractionator & 612 & 8.2 & 74.9 & 1.2 \\
\hline GW Granulator 2mm & Large fractionator & 363 & 8.8 & 41.2 & 1.5 \\
\hline GW ZRI 4min & Large fractionator & 403 & 9.0 & 44.9 & 1.5 \\
\hline GW UPZ 22000rpm & Large fractionator & 295 & 8.3 & 35.6 & 2.0 \\
\hline GW Press & Small fractionator & 87 & 9.4 & 9.2 & 2.4 \\
\hline GW RS200 & Small fractionator & 49 & 10.6 & 4.6 & 9.8 \\
\hline
\end{tabular}

* Length weighted average fiber length

** Average fiber width

*** Average particle length versus width

$* * * *$ Percentage of measured particles shorten than $20 \mu \mathrm{m}$

Figures

Fig $1-G W$ and RW samples used in the experiments. The GW was blowing wool and the RW was process waste/sawdust from a rock wool factory. The scale is shown with a centimeter ruler placed under the wools. At right are secondary electron microscope images showing magnifications of the mineral wools.

Fig 2 - Schematic of tube-fractionation equipment. 
Fig 3 - Four CCD photos of fractionated wool powder samples. a) refers to Rockwool (RW) sample, b) refers to Glasswool (GW) sample grinded with UPZ fine impact mill, c) refers to Rockwool (RW) sample pressed with hydraulic press and d) refers to Glasswool (GW) sample grinded with Vibratory disc mill (RS200).

Fig 4 - Loose bulk densities of the raw GW and RW samples and comminuted samples determined according to Standard SFS EN 1097-3. The standard deviations of the mean are marked with error bars but are not clearly visible, as they are an order of magnitude of 1.

Fig 5 - Untapped and tapped densities of the press and RS200 samples determined according to standard SFS EN 1237. The standard deviations of the mean are marked with error bars but are not clearly visible, as they are an order of magnitude of 1 . The densities of OPC are shown for comparison.

Fig 6 - Cumulative fiber-length distribution of GW samples determined with fractionators.

Fig 7 - Cumulative fiber-length distribution of RW samples determined with fractionators.

Fig 8 - Secondary electron microscope image showing the RW fibers comminuted with the ABCO Mega hydraulic press, the force of which squashed/agglomerated the fibers.

Fig 9 - Secondary electron microscope images of the GW and RW after comminution with the ABCO Mega hydraulic press and the Retsch vibratory disc mill (RS200). The press produced fibers $<100 \mu \mathrm{m}$ in length, while the RS200 transformed both samples into powder.
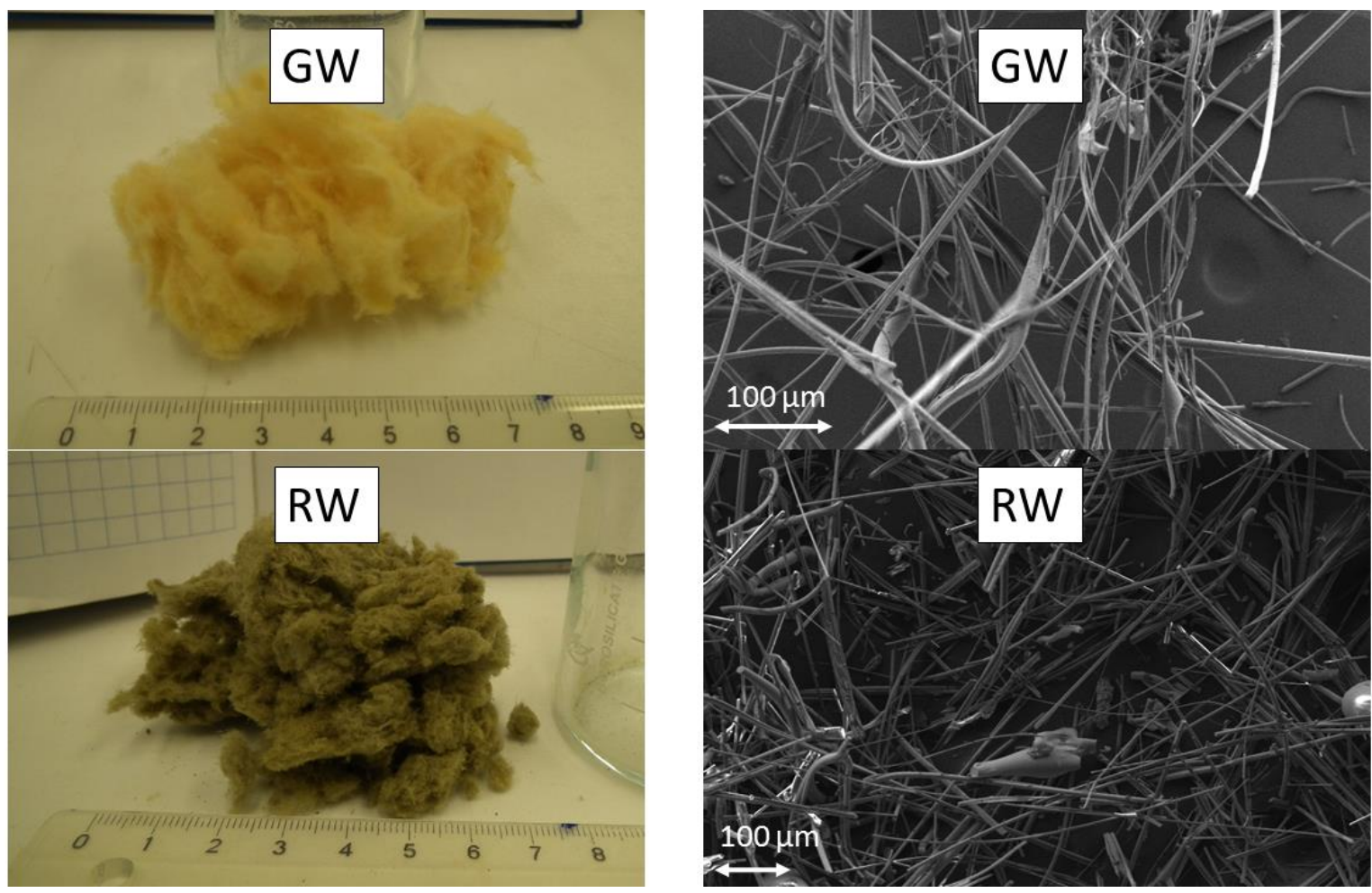

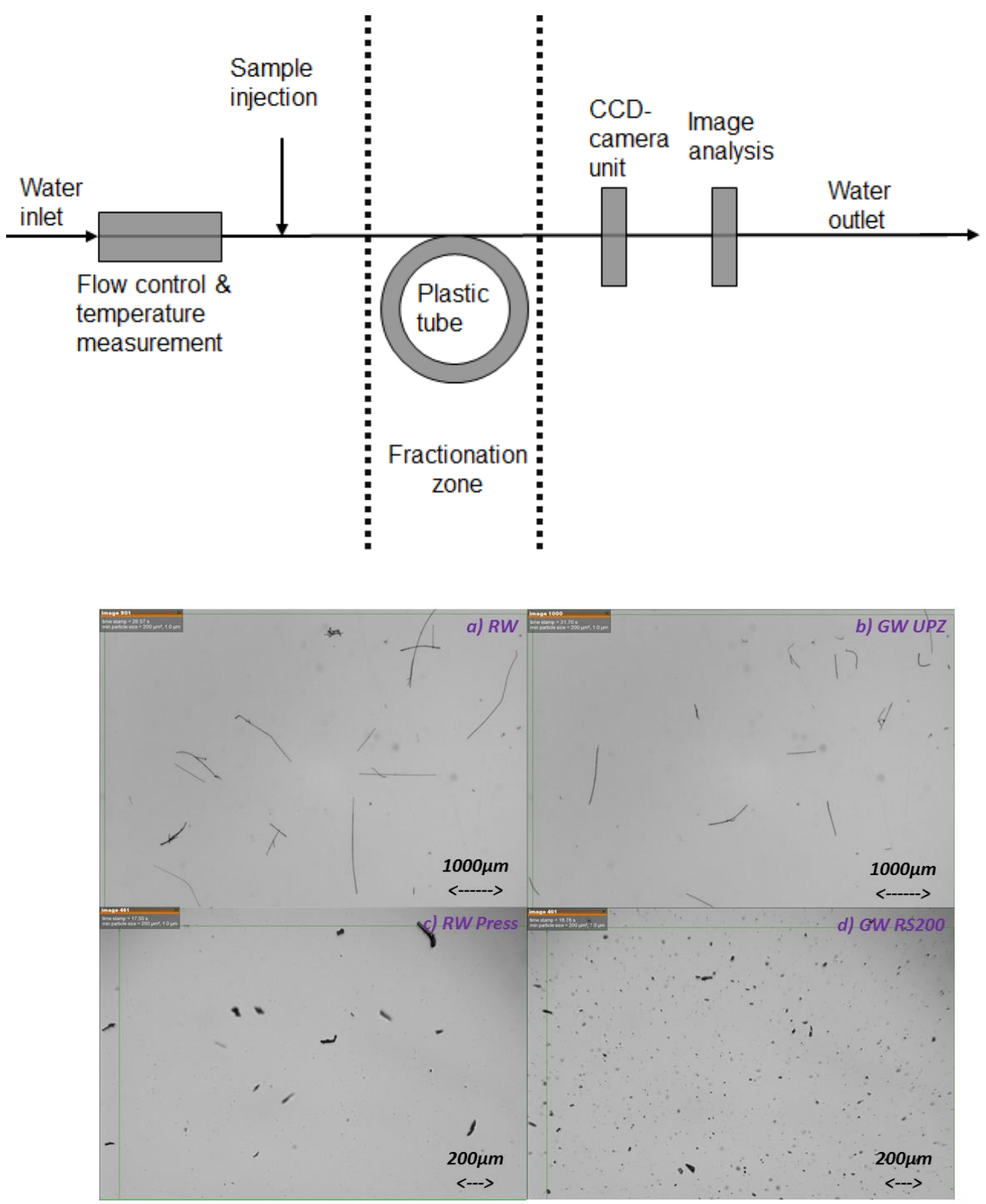

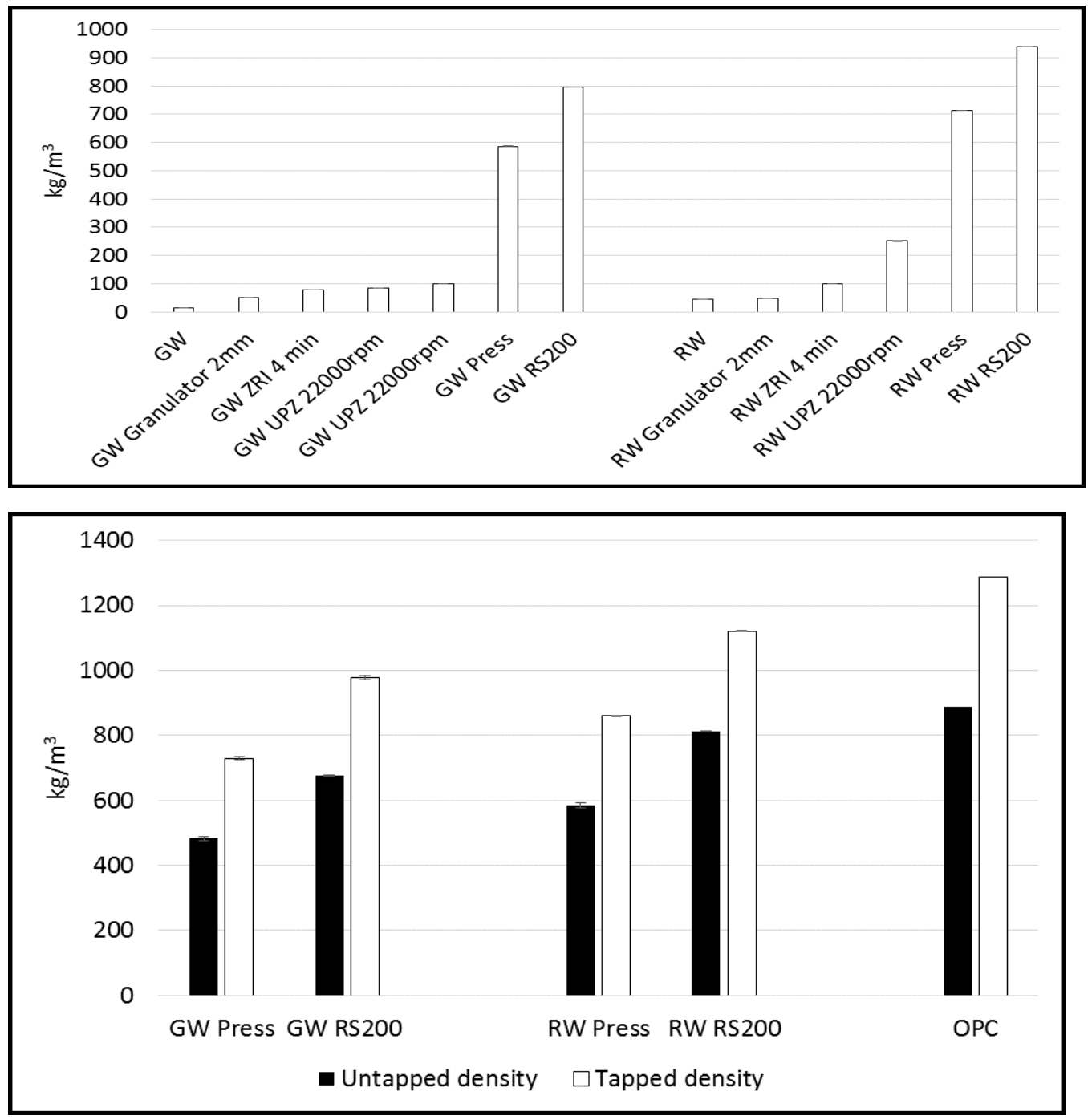

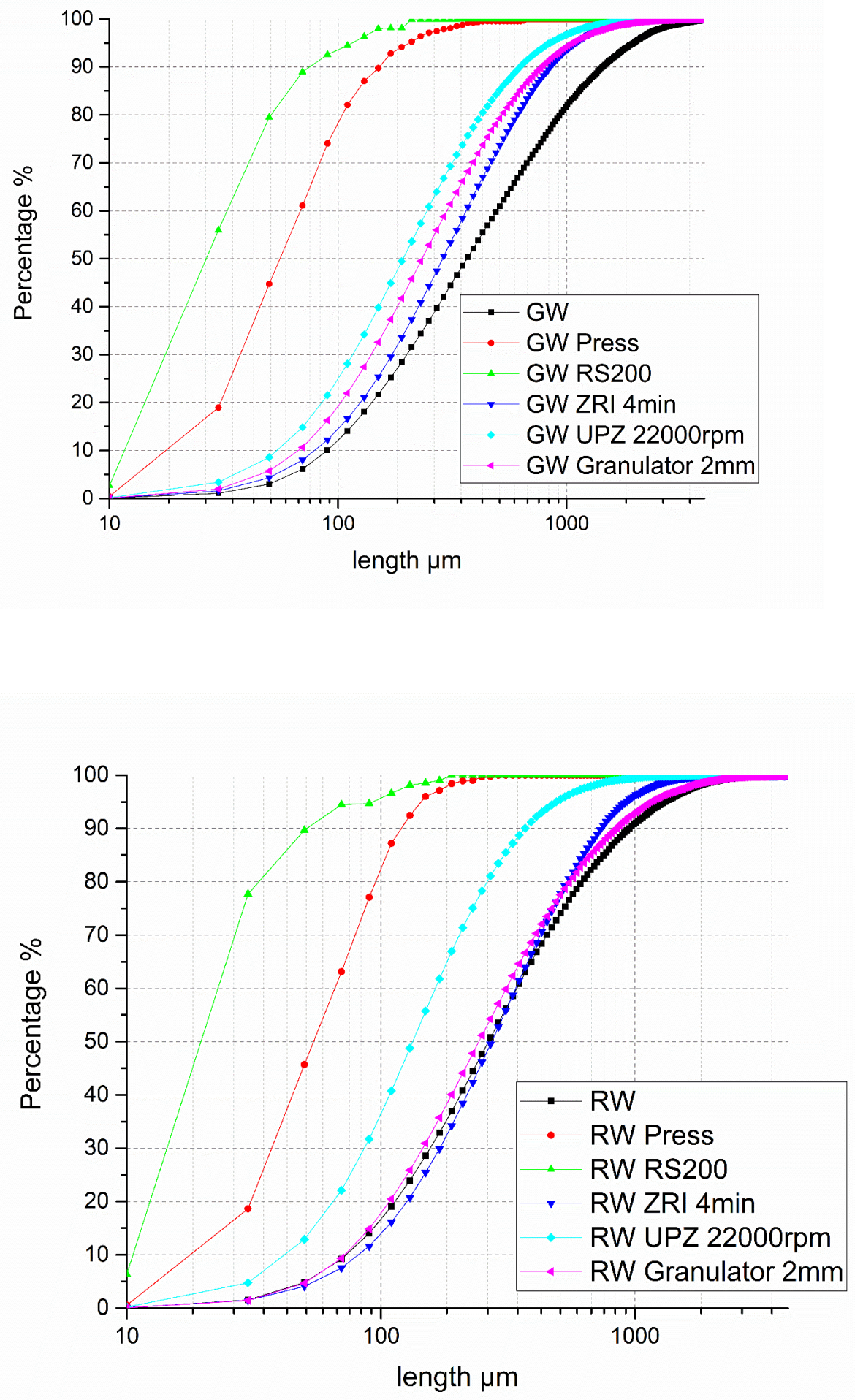

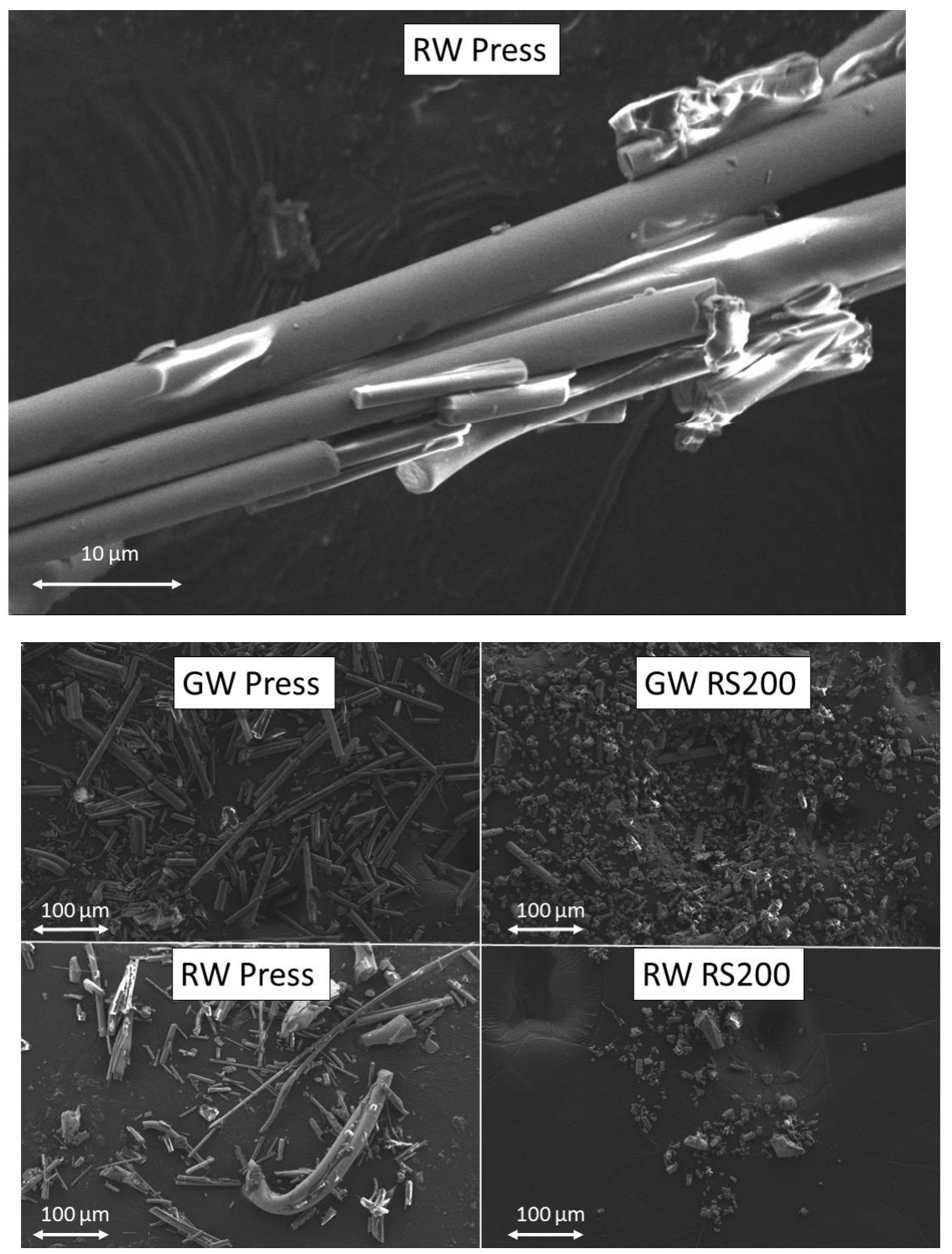

Appendix

Appendix A. Rapid 200 Series granulator. The upper part of the image shows the knives, below which are the screen and the grating.

Appendix B. The ZRI homogenizer. The material is fed into the center of the stator (on the table) and then forced through the high-frequency rotor. The processed material continues to the pipe above and is either collected or directed back for more processing.

Appendix C. UPZ mill chamber. The feeding screw (not shown) carries the material to the center of the stator pin disc (shown in the hands). The material passes through the pin mills due to the under pressure caused by the rotor disc. The processed material is collected in a container underneath.

Appendix D. The steel mold used with the ABCO Mega hydraulic press. 
Appendix E. Vibratory disc mill (RS200) grinding set. The material is loaded between the grinding ring and the grinding dish.

Appendix $\mathrm{F}$. The table below shows the variable parameters for the experiments conducted. From these experiments each comminution process was optimized to produce material of uniform quality. It was concluded that the optimized experimental conditions shown in Table 1 represent each comminution method properly. The feeding amount did not affect to the results significantly with Granulator, UPZ or ZRI. For Press and RS200 the feeding amount was maxed (the container was filled as much as possible). If lower amount would be used smaller particle sizes might be obtained. Milling time was affected mainly by feeding amount for Granulator, UPZ and ZRI (the material passed through the comminution device with constant speed so more time was consumed as more material was feeded). For RS200, smaller particles sizes can be obtained if longer milling time is used. For Press, the milling time does not affect as the used pressure is constant. The milling speed with UPZ and ZRI affected mainly to the process speed and material loss (see section 3.1), but not to the fiber length. For RS200, max milling speed (1500 rpm) was used, but lower speed is expected to lower comminution efficiency.

\begin{tabular}{|c|c|c|}
\hline Method & Parameters & Milling time \\
\hline Granulator & Sieve size: $2-6 \mathrm{~mm}$ & $\sim 1 \mathrm{~min}$ \\
\hline UPZ & $\begin{array}{l}\text { Feeding speed: } 100-188 \text { rpm; } 12,000-22,000 \text { rpm; With and without } \\
\text { cryo-unit }\end{array}$ & $1-5 \mathrm{~min}$ \\
\hline ZRI & $\begin{array}{l}260 \mathrm{~Hz} \text {; Fed as 3-5 m\%-water suspension; With and without IKA-mixer } \\
\text { as sample feeder }\end{array}$ & $10 \mathrm{~s} ; 1-6 \mathrm{~min}$ looping \\
\hline Press & Pressure: 10 tons $/ 12.6 \mathrm{~cm}^{2}$; Pressing time: $30 \mathrm{~s}$ & $30 \mathrm{~s}$ \\
\hline RS200 & Mill speed: 1500 rpm & $30 \mathrm{~s}$ \\
\hline
\end{tabular}

Appendix G. GW and RW after comminution with a Rapid 200 Series granulator with a 2-mm screen and a Hosokawa Alpine UPZ fine-impact mill. The scale is shown with a centimeter ruler placed under the wools.

Appendix H. GW and RW before and after comminution with the ZRI homogenizer and after filtering and drying. The scale is shown with a centimeter ruler placed under the wool.

Appendix I. GW and RW before and after comminution with the ABCO Mega hydraulic press and the Retsch vibratory disc mill. The scale is shown with a centimeter ruler placed under the wools. 

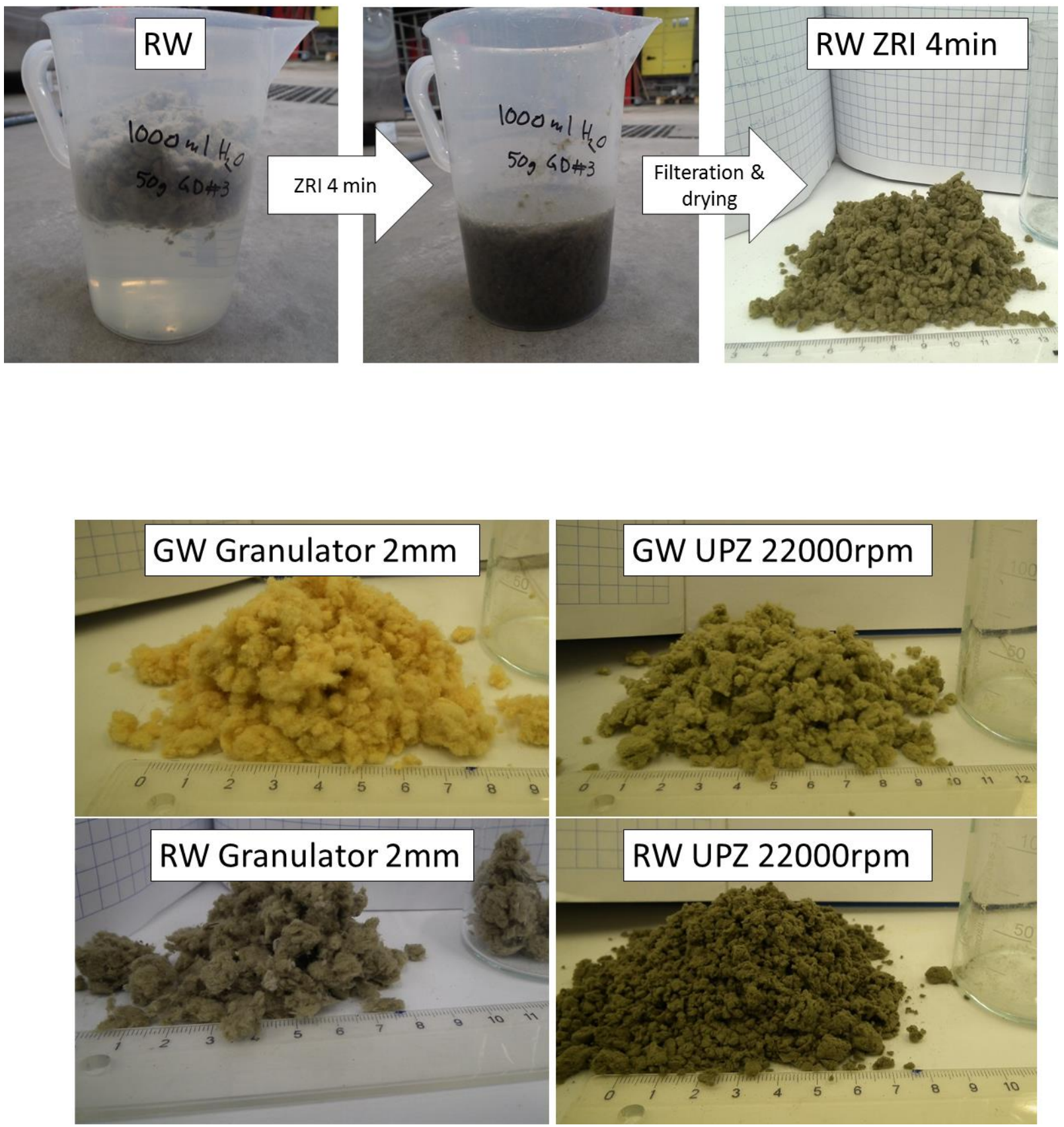


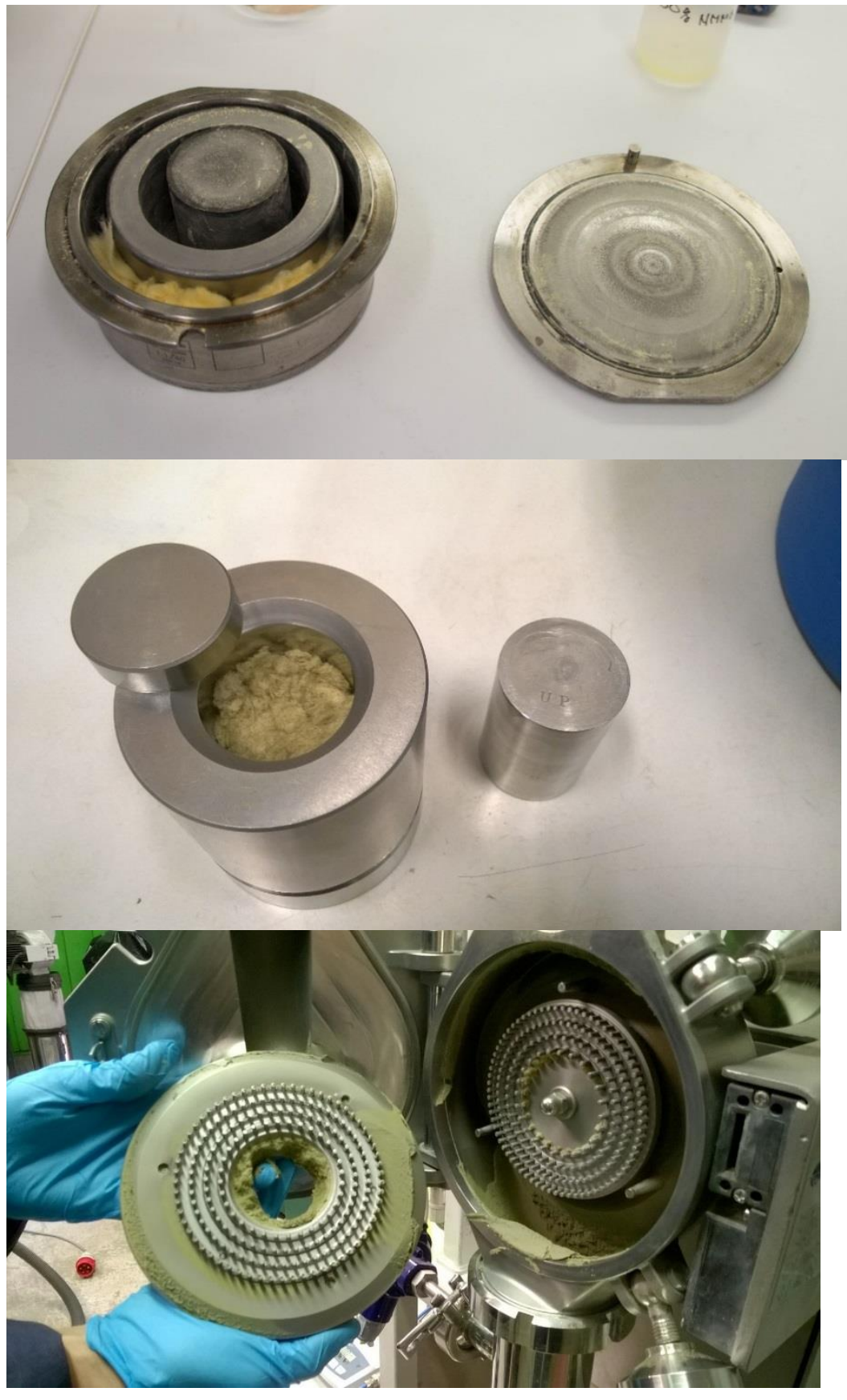




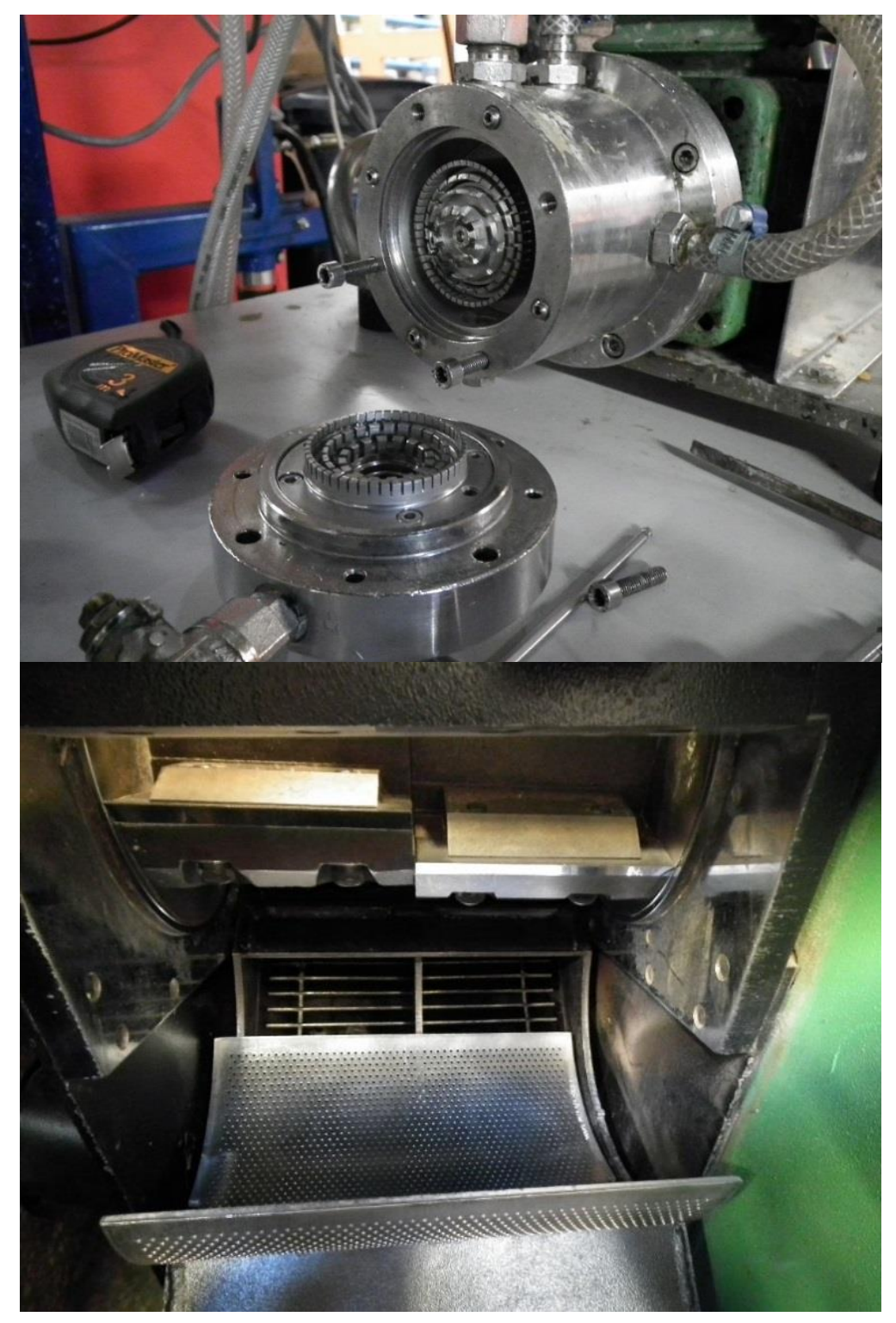



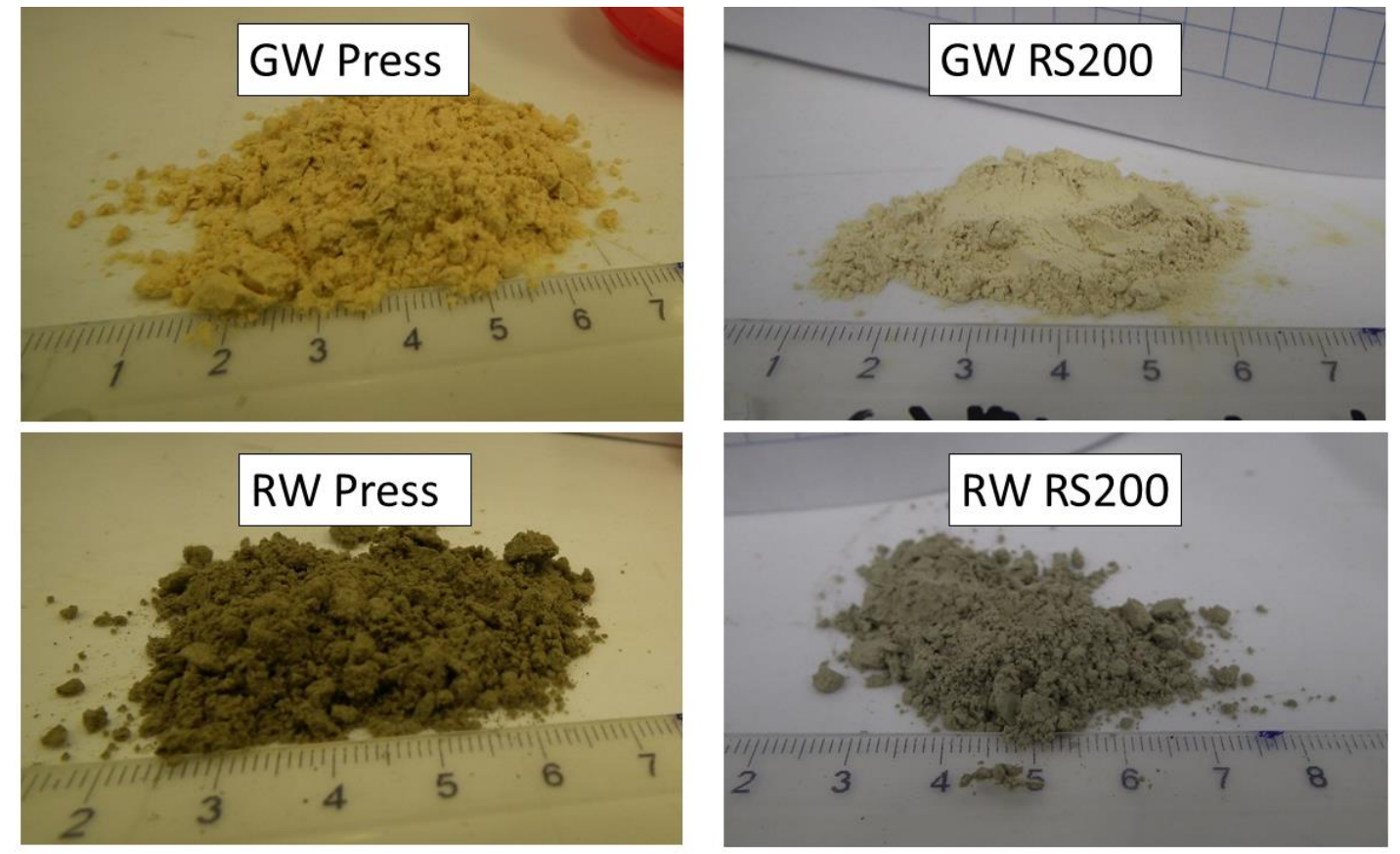